\title{
Integrating the Sustainable Development Goals (SDGs) into Urban Climate Plans in the UK and Japan: A Text Analysis
}

\author{
Leticia Ozawa-Meida ${ }^{1}$, Fernando Ortiz-Moya ${ }^{2}$, Birgit Painter ${ }^{1}$, Matthew Hengesbaugh ${ }^{2}$, Ryoko Nakano ${ }^{2}{ }^{(1}$, \\ Tetsuro Yoshida ${ }^{2}$, Eric Zusman ${ }^{2}$ and Subhes Bhattacharyya ${ }^{1, *(D)}$ \\ 1 Institute of Energy and Sustainable Development, De Montfort University, Leicester LE1 9BH, UK; \\ lozawa-meida@dmu.ac.uk (L.O.-M.); bpainter@dmu.ac.uk (B.P.) \\ 2 Institute for Global Environment Strategies (IGES), Hayama, Kanagawa 240-0115, Japan; \\ ortiz-moya@iges.or.jp (F.O.-M.); hengesbaugh@iges.or.jp (M.H.); r-nakano@iges.or.jp (R.N.); \\ yoshida-te@city.kawasaki.jp (T.Y.); zusman@iges.or.jp (E.Z.) \\ * Correspondence: subhesb@dmu.ac.uk; Tel.: +44-(0)116-257-7975
}

\section{check for}

updates

Citation: Ozawa-Meida, L.; Ortiz-Moya, F.; Painter, B.;

Hengesbaugh, M.; Nakano, R.;

Yoshida, T.; Zusman, E.;

Bhattacharyya, S. Integrating the Sustainable Development Goals (SDGs) into Urban Climate Plans in the UK and Japan: A Text Analysis. Climate 2021, 9, 100. https:/ / doi.org/ $10.3390 /$ cli9060100

Academic Editor: Chris Swanston

Received: 2 May 2021

Accepted: 14 June 2021

Published: 19 June 2021

Publisher's Note: MDPI stays neutral with regard to jurisdictional claims in published maps and institutional affiliations.

Copyright: (c) 2021 by the authors. Licensee MDPI, Basel, Switzerland. This article is an open access article distributed under the terms and conditions of the Creative Commons Attribution (CC BY) license (https:// creativecommons.org/licenses/by/ $4.0 /)$.

\begin{abstract}
Cities are increasingly adopting potentially sustainable climate plans. Integrating the Sustainable Development Goals (SDGs) into these plans could help stabilize the climate while generating jobs, narrowing equity gaps, fostering innovation, and delivering other sustainability benefits. Yet, how much cities are integrating the SDGs into climate plans remains poorly understood. This article shed light on this question with a text analysis of SDG "keywords" in climate plans for two British and two Japanese cities. The results revealed that none of the surveyed cities have connected climate with socioeconomic priorities covered in SDG1 (poverty), SDG8 (employment), SDG5 (gender), and SDG10 (inequalities). Meanwhile, the United Kingdom cities made more connections between climate and responsible consumption and production (SDG12) than the Japanese cities. Further, Kyoto, Japan shares a climate-SDGs linkages profile that resembles the United Kingdom cities more than Kawasaki. Though not without limitations, text analysis can facilitate the city-to-city peer learning needed to make urban climate plans sustainable within and across countries.
\end{abstract}

Keywords: local climate actions; cities; sustainable development goals; UK; Japan

\section{Introduction}

Addressing the climate emergency is among the most pressing challenges facing the world today. In recent years, many of the most innovative and ambitious responses to this challenge have emerged from cities. In many countries, cities have supplanted national governments as leaders in climate policy [1]. It is important that cities make this transition as they consume most of the world's energy and contribute around $70 \%$ of global carbon dioxide $\left(\mathrm{CO}_{2}\right)$ emissions [2]. Cities also occupy an expanded role because they are increasingly susceptible to heat waves, flooding, intense storms, and a litany of other adverse climate impacts [3].

Yet another reason cities warrant greater consideration in climate policy decisions is their potential for dynamic responses. Many cities have not sat by passively as temperatures increased. Instead, several cities have pro-actively responded to climate change. Some forward-looking cities have adopted policies and initiatives aimed at electrifying public transport, greening buildings, and incentivizing renewable energy. Other cities have invested in projects to climate-proof roads, reinforce sea walls, and upgrade emergency response systems. In many cases, cities have been able to capitalize on their flexibility and agility to quickly introduce and spread innovative solutions to climate change [1].

Yet, while a number of cities have moved quickly and confidently on climate change, not all have been convinced that early or bold action is needed. Moreover, even local authorities persuaded of the merits of such actions may have a scope for greater ambitions [4]. A critical and often missing link in a cities' decision-making calculus is how mitigating or 
adapting to climate change contributes to broader non-climate development objectives [5]. Forging links between climate and wider development goals may make acting on climate change appealing to more cities, while increasing the aspirations of those already ahead of the learning curve.

Aligning climate and broader sustainability objectives has many advantages for cities. One is that integrated, multi-objective policies tend to be more cost-effective than those focusing on a single, isolated issue. A second advantage is that policy conflicts and tradeoffs-for example, job losses from a shift to renewable energy — can be better anticipated and managed. A third is that seemingly marginal environmental issues (such as provisions of green space) may gain greater weight in decisions when paired with sometimes higher-profile climate objectives. Lastly, drawing linkages between climate and other sustainability objectives remains consistent with the letter and spirit of the Paris Agreement and the United Nations (UN) Sustainable Development Goals (SDGs). The bottom line is that cities could benefit from realizing synergies and managing trade-offs between climate goals and the SDGs [6].

Many advantages therefore exist to mainstream sustainability objectives in urban climate plans. However, whether and to what extent cities are making climate plans sustainable remains poorly understood. This paper aimed to shed light on this question by analyzing the integration of the 17 SDGs into climate action plans in two United Kingdom and two Japanese cities. The paper employed a novel text analysis to map the linkages in climate plans for each city individually and then compare integration between climate and other SDGs across the cities. It found that the surveyed Japanese and UK cities have yet to link SDG13 (climate) with goals related to socioeconomic issues such as SDG1 (poverty), SDG8 (employment), SDG5 (gender), and SDG10 (inequalities). The text analysis also revealed that the surveyed UK cities made more connections between climate and responsible consumption and production (SDG12). Finally, the text analysis demonstrated that Kyoto, Japan shares a mapping profile that is more similar to the surveyed UK cities.

The remainder of the paper is divided into four sections. Section 2 outlines possible linkages between climate actions and other SDGs. Section 3 describes the methodology used in our study, while Section 4 presents four case studies-Kyoto and Kawasaki from Japan and Bristol and Nottingham from the UK. Section 5 offers a comparative picture and some reflection on our key findings. Concluding remarks are then presented.

\section{Climate and SDGs Linkages in Cities}

In a rapidly urbanizing world, cities are engines of socioeconomic development, accounting for $80 \%$ of the global GDP [7]. Yet whether cities will be able to sustain development depends on how well they respond to interrelated impacts of global climate changes and other development concerns. Unless cities dramatically alter development trajectories, their own contributions to a warming climate could slim the prospects of a sustainable future. As such, cities have a pivotal role to play in achieving climate goals like those inscribed in the Paris Agreement. In fact, many cities have formulated and shared climate action plans with the help of networks and initiatives such as ICLEI, C-40 cities, and the Covenant of Mayors.

There are also growing opportunities to align city climate plans with the SDGs. Launched in 2015, the SDGs have opened opportunities to make connections between climate related activities and other environmental, social, and economic priorities. A number of goals are relevant to cities, and SDG11 (Sustainable Cities and Communities) is arguably the most pertinent. However, many other SDGs are relevant to cities even if they do not explicitly mention cities.

Often the most direct linkages exist between climate and other environmentally-related SDGs. A warmer climate will have clear implications for SDG6 (water), SDG7 (energy), and SDGs 14 (life under water) and 15 (life on land). For instance, warmer temperatures are already placing strains on urban water supplies-a stress that is likely to intensify without a shift in both climate and water management policies. The connection between 
climate responses and other environmental goals also works in the opposite direction. To illustrate, some carefully crafted climate mitigation and adaptation measures can also secure water, energy, and marine and terrestrial ecosystems. This is increasingly evident with the popularization of nature-based solutions such as urban gardens or rainwater capture and storage that can help cities become more green, livable, and resilient.

Another set of linkages involve connections between climate and socioeconomic SDGs. Poverty, equity, and climate are inextricably linked since poorer populations often inhabit areas exposed to extreme temperatures, sea level rise, flooding, and other climate risks. In addition, climate change will likely drive vulnerable populations towards urban centers, intensifying pressure on critical infrastructure and services [8]. Another climate-social link involves gender. Not only do more women live in poverty than men, they often lack the social standing and economic resources to adapt to changing climate, making it important for climate policies to factor in gender differentiated impacts [9]. Finally, there is clearly a connection between climate and employment and industrial development. More frequent and intense storms are already threatening small and medium-sized enterprises and could upend entire industries without more ambitious remedial efforts. At the same time, shifts to a green economy and efforts to make urban infrastructure resilient can create jobs and spark business models that contribute to a safer climate and achieve other SDGs [10]. A particularly attractive opportunity for cities in this space is making systems of consumption and production (SDG12) less resource-intensive and more sustainable-a change that will also lower emissions and build resilience.

Many of these connections between climate change and other environmental and socioeconomic goals are interrelated. It is therefore increasingly important to factor these dynamic interactions into urban climate policies and practices. At best, the lack of a connection between climate and other development goals could amount to a one-off lost opportunity. At worst, it could set off a cascade of effects that worsens inequality and deepens poverty among the most vulnerable communities for generations [11]. In consequence, accounting for multiple interactions in climate decisions is a growing development imperative for cities.

To some extent, cities have recognized the opportunities and implications of integrating sustainability into climate plans. For instance, some cities have offered economic incentives (tax reductions) for green businesses that facilitate a shift to a low carbon economy. Others have made some connections in their climate plans-for instance, noting some of the actions in those plans also helps deliver on certain SDGs. However, not all local authorities are moving at the same speed or tackling these issues with the same level of urgency; in general, there is significant potential to do more in this space.

An encouraging sign is that with the advent of the SDGs several tools and techniques has emerged to help policymakers realize this potential. For instance, some studies have mapped the energy-related and other SDGs [12]. The most commonly used approach is a seven-point framework that can help policymakers determine the direction and strength of interactions between different SDGs in a wide range of contexts [13]. Importantly, this approach has not only been adopted in countries such as Switzerland [14], but also been adapted for cities such as Quebec, Canada [15].

The use of these tools is particularly helpful for determining the future direction of urban climate policies. It offers less insight, however, into the current status and comparison across cities in forging climate-sustainability links. Part of the reason that there has been limited work chronicling this status or comparing cities is that the SDGs are not well defined at the city level. In addition, some goals may not be relevant at the local scale. This places constraints on the kind of data that might be available to examine these links.

There is nonetheless an opportunity to work around these challenges by using text analysis to examine existing climate plans. The use of these techniques may be particularly helpful for cities that are considering using some of the other tools to make existing climate plans more sustainable. 


\section{Materials and Methods}

Our study followed three main stages of analysis, as illustrated in Figure 1: screening, scoping, and systematic text analysis. Narrowing down from 20 cities in the screening stage, four case studies were selected for the systematic text analysis: two from Japan and two from the UK.

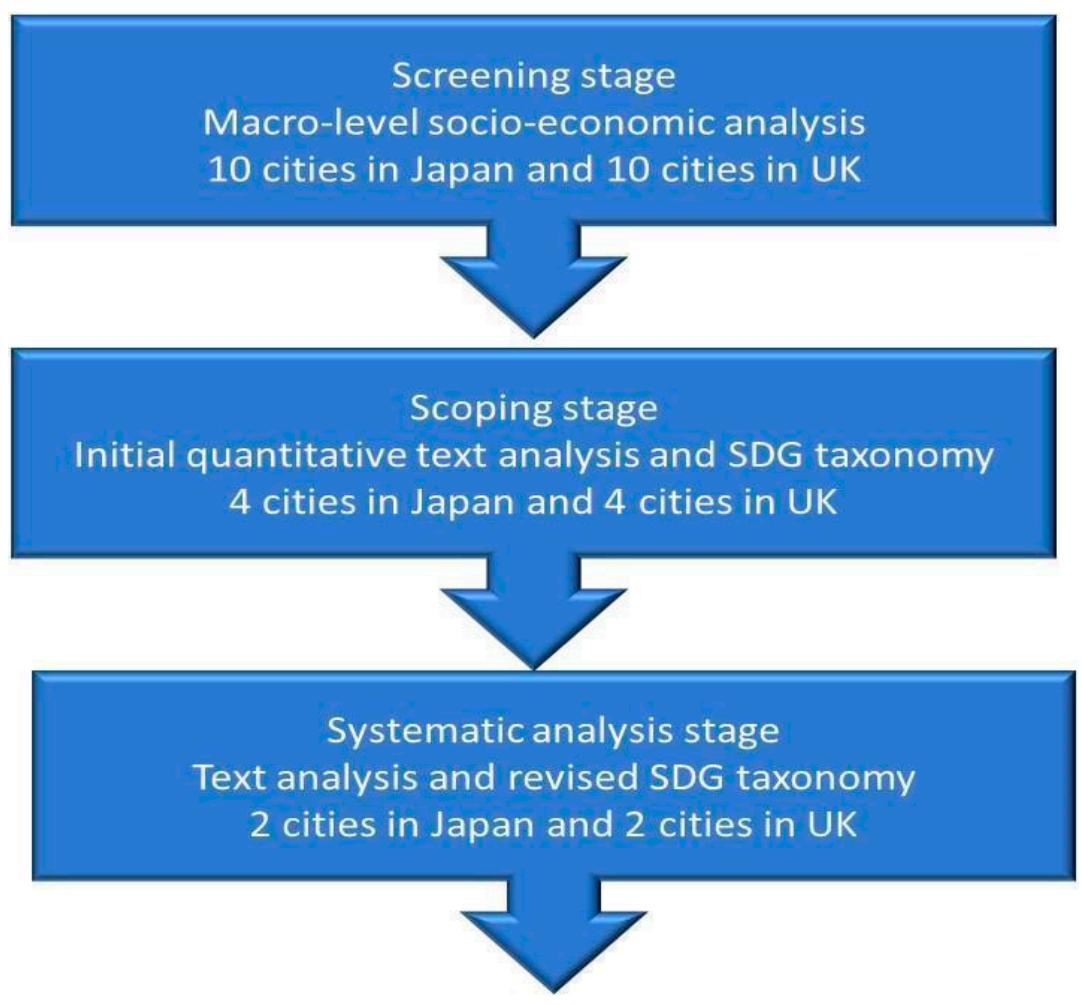

Figure 1. Research stages.

The purpose of the screening stage was to develop the big picture regarding climate action plans of UK and Japan cities as well as their alignment with the SDGs, starting from a macro-level perspective. The initial selection of ten cities in each country was informed by the availability of information about their urban area, population (smallsized cities were excluded), population growth, geographical position, socio-economic activities, coastal/inland, and national or international recognition of the city via environmental, social, or cultural awards. This stage involved a quick scan of council websites to find any relevant information about their climate mitigation, adaptation, and sustainable development plans.

Following the screening stage, four cities in Japan (Kyoto, Matsumoto, Kamakura, and Kawasaki) and four cities in the UK (Bristol, Leicester, Nottingham, and Milton Keynes) were selected for an initial text analysis based on the public availability of recent climate action plans and access to council staff for potential interviews. An initial quantitative text analysis using the qualitative software NVivo (version 12) [16] consisted of the examination of word frequency through the graphical representation either in word clouds or word trees to explore how different themes were associated in the documents, and a text query to identify keywords for each SDG based on their relevance in the targets for each SDG. The translation into Japanese of keywords used the terms of the official Japanese translation of the 2030 Agenda. An initial taxonomy of keywords was developed in this stage using 168 words (around 9 to 10 keywords for each SDG). Although the text query using the initial taxonomy provided relevant insights of the main priorities of the SDGs in the climate action plans of these cities, the analysis proved to be excessively time-consuming and complicated. In addition, results of this text query were heterogenous potentially due to the differences in the English and Japanese languages (and interpretation of the keywords). At this stage, 
interviews with key staff in the Energy, Sustainability or Climate Change departments in the city councils were also attempted to get insights of the opportunities and challenges to incorporate SDGs priorities in climate action plans. However, due to time constraints and travel restrictions associated with the COVID-19 pandemic, only interviews in the municipalities of Kyoto and Kamakura in Japan and of Nottingham and Leicester in the UK took place.

Based on the lessons learnt from the previous stages, a simplified and revised taxonomy of keywords was developed for the systematic analysis stage, to improve consistency and uniformity in both languages. Built upon the previous analysis, four cities-two from Japan and two from the UK-were selected for further systematic text analysis using the revised taxonomy shown in Table 1 to "code" and categorize the data. Keywords were searched, stored, and handled using the software program NVivo 12 [16]. The coding results, in terms of percentage coverage of the keywords in the documents, were plotted in hierarchical charts for each city as well as in a bar chart of all four cities, to facilitate a simpler and more transparent comparison. The qualitative analysis of the text passages of the coding results also allowed us to understand the context and priorities where the keywords of the SDGs were mentioned.

Table 1. Keywords used in the systematic text analysis.

\begin{tabular}{|c|c|}
\hline Sustainable Development Goal & Keyword(s) \\
\hline SDG1: No poverty & - Poverty (貧困) \\
\hline SDG2: Zero hunger & - Food (食料) \\
\hline SDG3: Good health and wellbeing & $\begin{array}{ll}\text { - } & \text { Health (健康) } \\
\text { - } & \text { Wellbeing (福祉) } \\
\end{array}$ \\
\hline SDG4: Quality education & $\begin{array}{ll}\text { - } & \text { Education (教育) } \\
\text { - } & \text { Schools (学校) } \\
\end{array}$ \\
\hline SDG5: Gender equality & $\begin{array}{ll}\bullet & \text { Gender (ジェンダー) } \\
\text { ・ } & \text { Girls/women (女児/女性) } \\
\text { ・ } & \text { Boys/men (男児/男性) } \\
\end{array}$ \\
\hline SDG6: Clean water and sanitation & $\begin{array}{ll}\text { - } & \text { Water (水) } \\
\text { - } & \text { Sanitation/treatment (衛生/排水処理) } \\
\end{array}$ \\
\hline SDG7: Affordable and clean energy & $\begin{array}{ll}\bullet & \text { Energy (エネルギー) } \\
\bullet & \text { Renewable (再生) } \\
\text { ・ } & \text { Grid (グリッド) } \\
\end{array}$ \\
\hline SDG8: Decent work and economic growth & $\begin{array}{ll}\text { - } & \text { Employment/jobs (雇用) } \\
\text { - } & \text { Economic growth (経済成長) } \\
\text { - } & \text { Business(事業) } \\
\text { - } & \text { Skills (スキル) } \\
\end{array}$ \\
\hline $\begin{array}{l}\text { SDG9: Industry, innovation, } \\
\text { and infrastructure }\end{array}$ & $\begin{array}{ll}\text { - } & \text { Industry (産業) } \\
\bullet & \text { Innovation (イノベーション) } \\
\text { - } & \text { Infrastructure (インフラ) }\end{array}$ \\
\hline SDG10: Reduced inequalities & $\begin{array}{ll}\text { - } & \text { Social inequalities (社会的不平等) } \\
\text { - } & \text { Equality (平等) }\end{array}$ \\
\hline SDG11: Sustainable cities and communities & $\begin{array}{ll}\text { ・ } & \text { Communities (コミュニティ) } \\
\text { - } & \text { Sustainable development (持続可能な開発) }\end{array}$ \\
\hline $\begin{array}{l}\text { SDG12: Responsible consumption } \\
\text { and production }\end{array}$ & $\begin{array}{ll}- & \text { Circular economy (循環型経済) } \\
\text { - } & \text { Resource efficiency (資源効率) } \\
\text { - } & \text { Waste (廃棄物) } \\
\end{array}$ \\
\hline SDG13: Climate action & $\begin{array}{ll}\text { - } & \text { Mitigation (緩和) } \\
\text { - } & \text { Adaptation (適応) } \\
\text { - } & \text { Resilience (強勒性 (レジリエンス)) }\end{array}$ \\
\hline
\end{tabular}


Table 1. Cont.

\begin{tabular}{lll}
\hline \multicolumn{1}{c}{ Sustainable Development Goal } & & \multicolumn{1}{c}{ Keyword(s) } \\
\hline \multirow{2}{*}{ SDG14: Life below water } & $\bullet$ & Marine ecosystems (海洋生態系) \\
& $\bullet$ & Aquatic ecosystems (水生生態系) \\
\hline \multirow{2}{*}{ SDG15: Life on land } & $\bullet$ & Wildlife (野生動物) \\
& $\bullet$ & Biodiversity (生物多様性) \\
& $\bullet$ & Conservation (保全) \\
\hline \multirow{2}{*}{ SDG16: Peace, justice, and strong institutions } & $\bullet$ & Peace (平和) \\
& $\bullet$ & Justice (司法) \\
& $\bullet$ & Institutions (制度) \\
\hline \multirow{2}{*}{ SDD17: Partnerships for the goals } & $\bullet$ & Partnerships/partners (パートナーシップ \\
& & / パートナー) \\
& $\bullet$ & Collaboration (協働 (コラボレーション)) \\
\hline
\end{tabular}

\section{Case Studies}

This section of the paper involves a preliminary review of the climate change plans of two cities in Japan: the large and well-known city of Kyoto; and the industrial city of Kawasaki. The two English cities are Bristol and Nottingham-Bristol is at the forefront of climate actions and sustainability whereas Nottingham is also active in climate actions but less focused on sustainability. The reviews look at whether and to what extent the linkages between climate and the environmental, social, and economic dimensions of sustainable development are evident in the cities' climate and other relevant plans. It also examines if there is any evidence in the documents of factors that facilitated or prevented integration across these issues.

\subsection{Kyoto}

\subsubsection{City and Climate Plan Background}

As the international birthplace of the Kyoto Protocol, the city of Kyoto is widely recognized as an agenda setter on climate and environmental policies. Located in the western center of Japan and occupying roughly $4600 \mathrm{~km}^{2}$, Kyoto is a thriving city of 1.47 million people. A historical city, by turns both traditional and modern, Kyoto's main industries include tourism, research, manufacturing, and services, and its estimated GDP per capita was US 41,410 in 2015. Kyoto carries a designated city status, meaning that it has been granted administrative functions typically reserved for Japanese Prefectural Governments.

In 1997, Kyoto was one of the first cities in the world to announce its planned adoption of global warming countermeasures. Subsequently, in 2004, the city officially enacted a directive outlining its efforts to address climate change. This led to the formulation of Kyoto's climate action plan in 2006, which has since been modified several times to ratchet up emissions reduction targets in line with national and international commitments. The current plan-last revised in 2017-pledges to reduce 1.335 million tons of GHG emissions by 2020, reaching zero carbon by the latter half of the 21st century through a combination of 98 actions, 36 policies, and 19 directions, all comprised under Kyoto's six visions for a low carbon society. The six visions include a focus on transit and mobility, forest restoration, energy and recycling, environmentally friendly lifestyles, green economic activities, and waste reduction, respectively. A new plan is currently in consultation stage, which pledges to make Kyoto carbon neutral by 2050.

Accordingly, Kyoto's action plan sets out emissions reduction priorities for the immediate (present-2020), medium (2030-2040), and long-term (2050 and beyond). Thirteen mitigation strategies have been proposed, clustered under the following sectors and activities: residential, commercial, industrial, transport, waste, addressing GHGs excluding carbon dioxide, and other reduction actions, all defined by a suite of supply and demandside policy measures. The action plan also features a section on climate change adaptation, highlighting actions to build resilience against natural disasters, protect health and safety, and minimize impacts on aquatic resources and ecosystems. 


\subsubsection{Integration between Climate and Other Dimensions of Sustainable Development}

Kyoto's action plan puts forward a number of policy measures focused on environmental conservation, resource management, and pollution prevention. Nature-based urban planning solutions are referenced throughout the plan, such as expanding the number of green spaces, utilizing biomass for heating, and introducing porous pavement to improve water quality and drainage. Other proposals include constructing sustainable buildings, increasing energy efficiency and the use of renewables, encouraging pedestrian access by widening public transportation options and the availability of eco-vehicles, and enhancing waste reduction efforts.

Another key facet of Kyoto's climate action plan is an emphasis on citizen engagement. Local residents are identified as having an important role to play in carrying out the plan's stated goals and objectives, which is clearly reflected in several policy proposals. For instance, the plan discusses making use of information and education campaigns, community partnerships, and incentives for the promotion of more eco-friendly lifestyles. On the other hand, little mention is given to issues of social inclusion and equity: Whereas compact land use planning is highlighted as one solution to addressing the needs of the elderly, for example, the plan does not indicate how similar interventions might be tailored to other vulnerable individuals, such as persons with disabilities.

The plan also presents a range of strategies and measures aimed at mobilizing the private sector to take action on climate change. In addition to proposing carbon offsetting, renewable energy mandates and the introduction of $\mathrm{CO}_{2}$ reduction plans for business, the plan highlights the need for public-private partnerships to incubate low-carbon technologies and initiatives. Green procurement is also listed as a means towards this end [17].

Vertical and horizontal cooperation are important considerations taken up by Kyoto's climate action plan. Kyoto maintains strong ties with the national government since being inducted in Japan's "Eco-Model City" program in 2013: and to this day utilizes the platform to leverage funding and engage with other local authorities on climate issues. The city also participates in international networks on climate change including as a member of ICLEI and the Covenant of Mayors. Further, Kyoto also maintains sister city status with Paris.

\subsection{Kawasaki}

\subsubsection{City and Climate Plan Background}

Kawasaki is the second largest city of Kanagawa Prefecture, after Yokohama, and one of the core cities of the Greater Tokyo Metropolitan Area. It has a population of over 1.5 million. Kawasaki has an area of $143.01 \mathrm{~km}^{2}$, stretching east-west in a narrow band in between Tokyo and Yokohama in the South bank of the Tama River.

Due to its strategic location, the city grew in importance during Japan's Industrial Revolution (i.e., Meiji (1868-1912) and Taisho (1912-1926) periods), rapidly industrializing alongside rapid urbanization. This process accelerated during the post-war era, when Japan's economy and population exploded. New train lines connected the city with Tokyo and Yokohama while residential areas developed along them. Manufacturing industries concentrated along the Tama River and the coast while residential areas spread over to the west. However, and similar to other Japanese cities of the time, uncontrolled industrialization brought about pollution problems.

Kawasaki has been at the forefront of Japan's environmental protection movement. In 1976 Kawasaki became the first city in the country to pass an ordinance on environmental impact assessment. Ever since, the city has always been "one of the first" in Japan in taking environmental action. Among other initiatives, in 1997, Kawasaki was one of the first four cities part of the "Eco-Town Project," at that time promoted by the Ministry of International Trade and Industry and the Ministry of Health. As part of this program, Kawasaki created an "eco-town" to serve as an incubator of industries dealing with the recycling of industrial waste. The eco-town simultaneously addressed the decline of the city's traditional heavy industries and growing environmental concerns [18]. 
In 1998, Kawasaki launched its own "Kawasaki's Challenge to Prevent Global Warming: An Action Plan for Preserving the Global Environment" to promote the reduction of GHG emissions. This was followed by the "Kawasaki Ordinance on the Promotion of Global Warming Countermeasures" in 2009 and the "Kawasaki City Basic Plan for the Promotion of Global Warming Countermeasures" in 2010. Ever since, Kawasaki has continued reinforcing its efforts towards climate action. The city has achieved a reduction of $16.8 \%$ in its GHG emission in 2015 compared to 1990 levels [19]. The city has committed to achieve carbon neutrality by 2050 .

\subsubsection{Integration between Climate and Other Dimensions of Sustainable Development}

The current "Kawasaki Basic Plan for the Promotion of Global Warming Countermeasures" (in short, basic plan) is based upon the city's "Ordinance on the Promotion of Global Warming Countermeasures" and includes an implementation plan. While the basic plan's focus is on mid-term objectives (mainly to 2030 with references to 2050), the implementation plan focuses on concrete measures to be implemented in the short term. The basic plan includes both mitigation and adaptation measures to both reduce GHG emission and to address the medium- and long-term impacts of climate change.

The guiding principle of the plan is to advance a low-carbon society through concrete measures that yield a number of co-benefits for the city. The underlying idea is that many of the proposed measures towards mitigation and adaptation will help address other social and economic issues facing the city. This, the plan notes, is in line with the holistic approach to sustainable development at the core of the SDGs. Among the expected co-benefits are an improvement in livability and quality of life standards in the city, to increase the city's resilience in the case of disaster due to a decentralized energy system based on renewable energy, or the promotion of new and green industries in Kawasaki's industrial park.

To achieve its main objective, the plan is structured around five main guiding principles: (1) reducing greenhouse gas emissions; (2) promoting renewable energy and energy efficiency; (3) promoting the adaptation to climate change; (4) contributing to developing new environmental technologies and industries; and (5) promoting the cooperation and collaboration among citizens, businesses, and the government. Based on these guiding principles, the plan presents 12 policy directions resulting in 30 concrete measures to achieve the reduction of $30 \%$ of GHG emissions by 2030 . These 12 policy directions are cross-sectoral in scope a wide range of aspects, such as lifestyles, energy efficiency in buildings, or the promotion of green spaces among others.

\subsection{Bristol}

\subsubsection{City and Climate Plan Background}

Bristol had an estimated population of 463,400 inhabitants in 2020 [20]. The city is located about $190 \mathrm{~km}$ west of London at the convergence of the rivers Avon and Frome in South Gloucestershire. It is the largest city in the south-west region and the eighth largest city within England and Wales. Bristol is a unitary authority with an elected mayor since 2012. The city accounts for 70\% of the population of the built-up area often referred to as "Greater Bristol" or the "Bristol Urban Area".

Due to its coastal location and as a major seaport, Bristol has a long history of trading commodities ranging from fresh produce, wine, grain, timber, and petroleum products to motor vehicles. Currently, the major economic activities in the city relate to the aerospace and advanced engineering industry, creative and digital media, electronics and information technology, and financial service sectors.

The city of Bristol is leading in many areas of climate action: It was the first UK city to develop a climate strategy in 2004 [21]. Since then, the city has developed and delivered a series of strategies and action plans in order to improve the environment of the city and reduce its contributions to climate change supported by large investments in transport improvements as well as in energy efficiency and renewable energy. This long-term commitment was recognized by the European Commission and the city was 
awarded as the first European Green Capital in 2015 [22]. It was also the first UK council to declare a climate emergency in 2018 and set out the goal of becoming carbon neutral and climate resilient by 2030 .

\subsubsection{Integration between Climate and Other Dimensions of Sustainable Development}

Since the recognition of European Green Capital, the city has developed a strong vision to become a fair, healthy, and sustainable city for all by 2050, which was set out in a comprehensive and integrative "One City Plan" [23]. The first iteration of this city plan launched in January 2019 was developed through extensive consultation and citizen engagement, bringing together the city council and existing city boards. The framework of the One City Plan explicitly integrates a commitment to the SDGs by establishing aspirations for 2050 in six priority themes: connectivity, economy, environment, health and wellbeing, homes and communities, and learning and skills. There is clear commitment and leadership of Bristol on monitoring progress and action towards the SDGs, which is demonstrated in it being the first UK city to produce and publish a Voluntary Local Review report focusing on all SDGs in 2019, among few other cities around the world [24].

To achieve the vision of the 2050 One City Plan, thematic boards constituted by city leaders in the respective themes will meet regularly (four times a year) and monitor the progress and iterate actions and goals of the priority themes. Targets and programs of works are set in the short, medium, and long term, to define goals and new pathways (2019-2029), to move forward with a universal approach of city living (2030-2039) and to achieve inclusivity, fairness, and sustainability in the city (2040-2050) [23]. Under the framework of the comprehensive city plan, Bristol's Environmental Sustainability Board coordinated the development of the "One City Climate Strategy for a Carbon-NeutralCarbon-Resilient Bristol by 2030" with inputs of other city boards, and which has been supported by the Bristol Advisory Committee on Climate Change. This strategy considers mitigation and adaptation in an integrated manner through a set of actions required in ten key areas: transport; buildings; heat decarbonization; electricity; consumption and waste; business and the economy; public, voluntary, community, and social enterprise services; natural environment; food and infrastructure interdependencies [21].

Despite a decrease in total and per capita carbon dioxide emissions from 2.23 to $1.55 \mathrm{Mt}$ (2010-2018) and from 6.44 to 4.68 tons per person (2010-2016), respectively, the city recognizes the challenges of becoming carbon neutral due to its high reliance on imported goods and services and their related supply chain emissions, as well as the business-related emissions of a thriving economy [24]. The strategy proposes to develop a citywide shared understanding of and commitment to responsible consumption through comprehensive and sustained communication and engagement campaigns across the public and businesses with emphasis on areas and activities with higher levels of consumption. In terms of climate resilience, the city recognizes the physical, social, and economic impacts that climate hazards, such as flooding and extreme heat, can impose on homes, businesses, schools, community assets, and critical infrastructure. Therefore, the strategy focuses on delivering green and blue infrastructure that can provide co-benefits for the health and wellbeing of the citizens as well as strengthening collaboration across infrastructure systems related to heat, electricity, water, ICT, and transport. To deliver this ambitious strategy, it is required that knowledge, capacity, and skills are shared across businesses, individuals, and community groups within and outside Bristol with the support of local partnerships and networks, such as the Bristol Green Capital Partnership, and international partnerships, such as the Global Parliament of Mayors and EUROCITIES.

\subsection{Nottingham}

\subsubsection{City and Climate Plan Background}

Nottingham, with a population of 330,000, lies in the center of the largest urban area in the East Midlands of the UK. It is tightly integrated with its surroundings and forms a metropolitan economy that is the seventh largest in the country. The city of Nottingham 
is governed by a unitary authority, Nottingham City Council, whilst the surroundings of Greater Nottingham are governed by Nottinghamshire County Council and several district and borough councils.

Historically, Nottingham's prosperity was based on a strong textile industry, which, however, fell into decline in the second half of the 20th century. The city then experienced a period of urban growth that came to an end around the turn of the millennium. As for many urban centers in the UK, this has been followed by pressure for further affordable developments, and challenges in terms of managing commercial and social development whilst meeting environmental concerns, such as maintaining the green belt.

In 2009, "One Nottingham", the city's local strategic partnership that brings together the public, private, voluntary, community, and faith sectors to work for change in the city, set out their overall strategic direction and long-term vision for the economic, social, and environmental wellbeing of the city of Nottingham in the Sustainable Community Strategy, whilst Nottinghamshire County Council published their "Sustainable Community Strategy 2010-2020". This was further accompanied by the City's 2020 Energy (and Carbon) Strategy in 2010, which covered domestic, commercial, public and industrial infrastructure, energy saving, energy generation and transport, and the Sustainable Energy Action Plan (SEAP) for the EU Covenant of Mayors, also in 2010.

\subsubsection{Integration between Climate and Other Dimensions of Sustainable Development}

Thus, Nottingham has a solid record of strategic development in terms of sustainability and community, although more recently the city's focus has been around energy savings and carbon emission reductions. Particular strengths are low carbon transport, with electric public transport options, including the NET tram system, which was introduced in 2004 and expanded in 2015, and low carbon heating.

Nottingham City is recognized internationally through its role as a Lighthouse City partner in the EU project REMOUrban, wherein the city helped to develop and demonstrate a sustainable urban regeneration model leveraging the convergence of energy, mobility, and ICT to transform European cities into smart cities [25].

Nottingham city has already met its energy strategy target and aims to become the first carbon neutral city in the UK by 2028. This ambition is outlined in the Carbon Neutral Charter and the Carbon Neutral Nottingham Action Plan 2020-2028.

The city acknowledged the challenge of climate change by declaring a Climate and Ecological Emergency in January 2020 and developed a charter that recognizes that "tackling climate change needs to be done in a way that is fair and sustainable-improving and protecting [the] environment, economy and society" [26]. The Carbon Neutral Action Plan builds on this and sets out high-level objectives in four main areas: carbon reduction, carbon removal, resilience and adaptation, and ecology and biodiversity. The first theme is further split up into five sections: transport, built environment, energy generation, waste and water, and consumption.

The declared focus of both the charter and the action plan is on "sustainable carbon neutrality", and the action plan framework specifically highlights crucial cross-cutting themes such as inclusivity, health, safety, and quality of life. Although no direct link is made to the UN SDGs, a shared vision is presented that acknowledges sustainable development thinking, e.g., "an approach that not only positively addresses wider environmental challenges but improves quality of life and builds a new form of clean growth for our economy through a green industrial revolution" and aims "to create a prosperous, fair and resilient city for this and future generations". The city is thus building on the success of meeting its 2020 energy strategy emissions target of reducing carbon dioxide emissions by $26 \%$ and is implementing a flexible framework that utilizes a wide range of co-benefits and partnerships. 


\section{Comparative Analysis}

This section presents the results of our text analysis using NVivo. Figure 2 presents a comparative picture of the prominence of SDG related keywords in the climate action plans of four cities considered in this study whereas Figure 3 presents the comparative distribution of keywords. The results are further discussed below for each city.

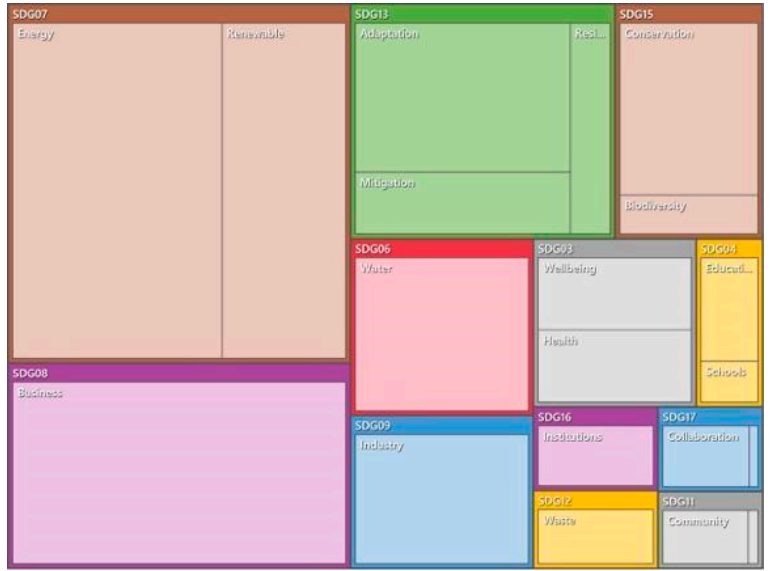

(a) Kyoto

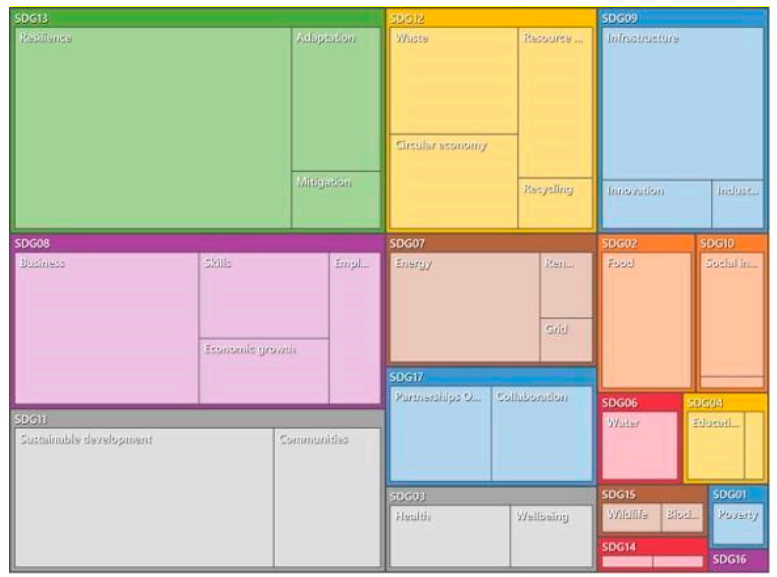

(c) Bristol

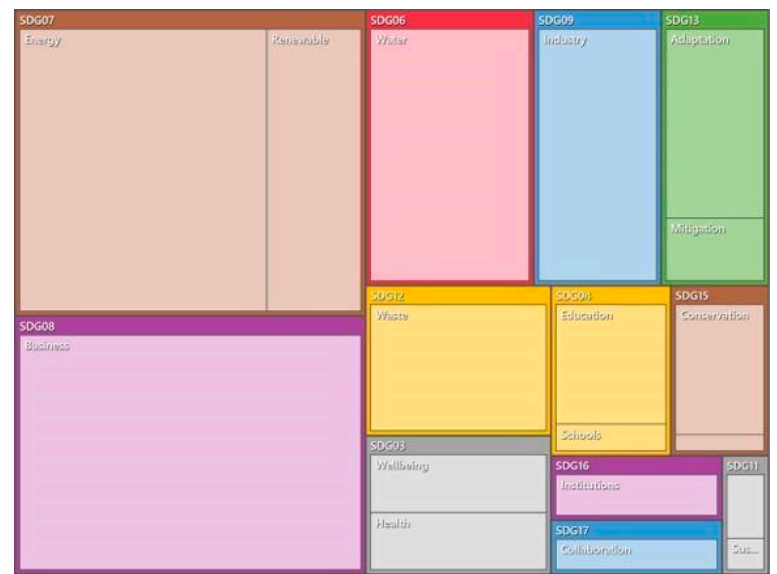

(b) Kawasaki

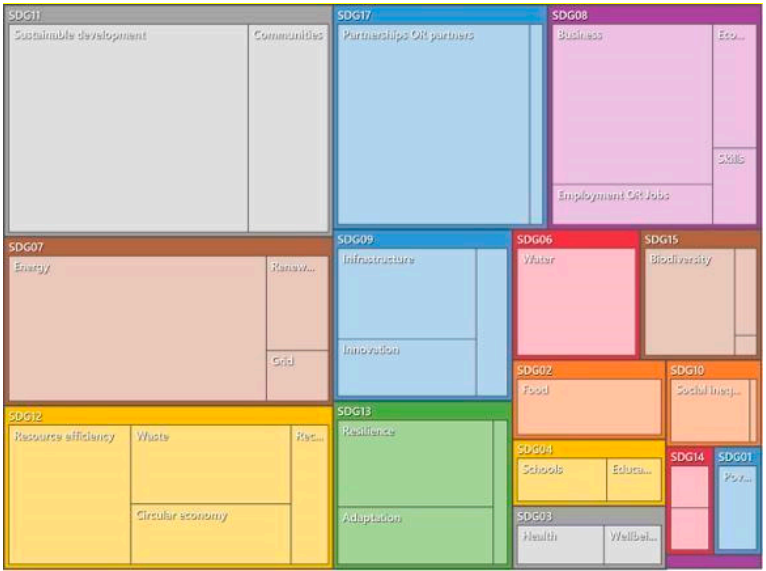

(d) Nottingham

Figure 2. Hierarchy charts comparing prominence of SDGs in selected Japan and UK cities: (a) Kyoto; (b) Kasawaki; (c) Bristol' and (d) Nottingham. 


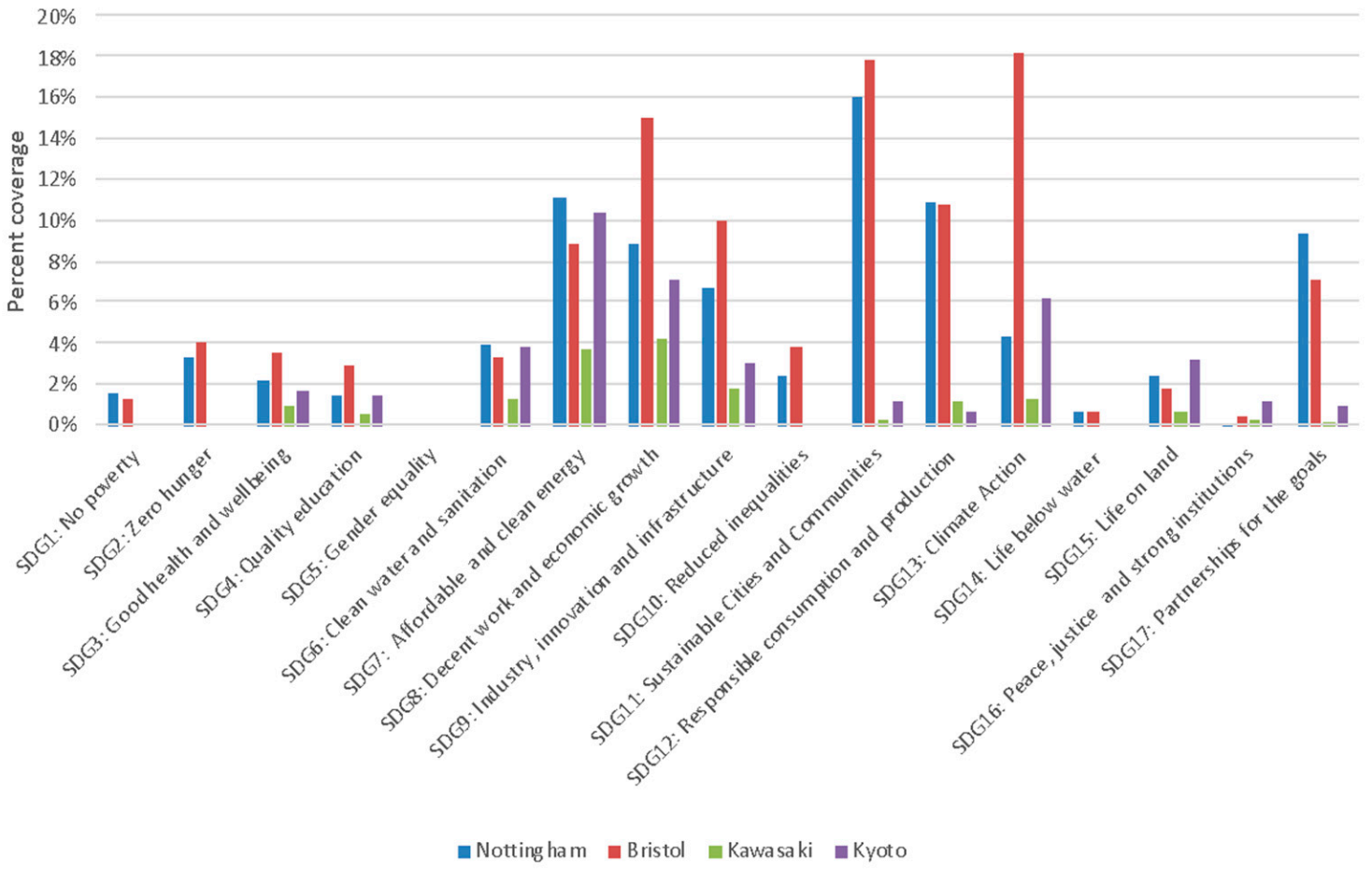

Figure 3. Percentage coverage of SDGs keywords in the climate plans of selected Japan and UK cities.

\subsection{Kyoto}

The document analyzed was the draft version of the "Kyoto City Global Warming Prevention Plan (2021-2030)" [17], which is currently in public consultation stage. This plan was drafted following the city's declaration of its intention to achieve carbon neutrality by 2050; it also sets up long-term strategies to decarbonize the city by that date. The plan sets an interim target of 40\% reduction when compared with 2013 levels by 2030 .

The text analysis reveals that the highest scoring SDGs are goals 7, 8, and 13. Among them, SDG7, affordable and clean energy, clearly outperforms every other goal, demonstrating the importance of the energy sector in decarbonization plans. Second to SDG7 is SDG8, decent work and economic growth, thus highlighting the economic significance of decarbonization for the city's future development. SDG13, climate action, also features prominently, especially in regard to adaptation to climate change. This might be related to the adverse climate-related events that have struck Japan in recent years. SDG3, good health and wellbeing; SDG6, clean water and sanitation; SDG9, industry, innovation, and infrastructure; and SDG15, life on land also scored higher than average counts in the text analysis. The prevalence of this wide range of SDGs reflects the plan's own commitment to be cross-sectoral in spirit, covering social, economic, and environmental SDGs.

On the other hand, the text analysis showed fewer matches in SDGs 4,11, 12, 16, and 17. No matches were found for SDGs 1, 2, 5, 10, and 14. However, the actions proposed in the plan hold the potential to have a positive impact on the abovementioned SDGs, since some of the expected benefits might reach across goals and targets. For example, prioritizing work-life balance will yield additional benefits for SDG5.

\subsection{Kawasaki}

The analysis of Kawasaki's climate action was based on the "Kawasaki City Global Warming Countermeasures Implementation Plan, First Period (2018-2021)". The plan aims at reducing more than 30\% of the city's GHG emission by 2030 from baseline year 1990. It will achieve such objective through 30 different measures [19]. 
The text analysis revealed that SDG7 is the most prominent goal across the plan, closely followed by SDG8. SDG6 ranks third but well below. Above average matches are SDGs 9, 12, and 16. The lower coverage across different SDGs might be explained by the plan's short-term nature (covering just 3 years) that emphasizes urgent actions to mitigate climate change and the expected economic co-benefits.

SDGs $3,4,11,15,16$, and 17 returned fewer than average matches. Similar to Kyoto's analysis, no matches were found for SDGs 1, 2, 5, 10, and 14. These findings reinforced the above-mentioned focus on short-term measures and strategies rather than an integral mid-term vision to 2030 or a long-term target to 2050 .

\subsection{Bristol}

The document analyzed was the "Bristol One City Climate Strategy, A Strategy for a Carbon-Neutral-Climate-Resilient Bristol by 2030" [21]. This strategy sets ambitious goals to become carbon neutral and climate resilient by 2030 as part of a comprehensive "One City Plan" for Bristol to 2050 [23].

Based on the text analysis, the most salient SDGs in this strategy relate to climate action (SDG13) (18\%), sustainable cities and communities (SDG11) (18\%), and decent work and economic growth (SDG8) (15\%). The integrative approach to adaptation and mitigation aligns well with the long-term vision of the One City Plan of becoming a fair, healthy, and sustainable city by 2050, where measures are proposed based on robust evidence of direct and indirect GHG emissions as well as local climate related risks. The prominence of SDG11 and SDG8 is not surprising as the climate strategy puts a strong emphasis on the engagement with communities, businesses, and individuals based on its collaborative and learning principles. This strategy also recognizes the relevance of SDG12 (responsible consumption and production) (11\%) and SDG9 (industry, innovation, and infrastructure). The strategy proposes the development of new circular economy business models focused on waste reduction and sustainable consumption, not only to reduce emissions related to waste management, but also to reduce vulnerabilities associated with international supply chain. In addition, the strategy also acknowledges the importance of understanding the infrastructure interdependencies (green, blue, and gray infrastructure as well as social infrastructure) to become more climate resilient.

Lower keyword coverage was found for SDGs associated with societal goals related to the reduction of inequalities (SDG10) $(4 \%)$ and poverty (SDG1) $(1 \%)$ as well as for zero hunger (SDG2) (4\%) and health and wellbeing (SDG3) (4\%). For SDG1 and SDG10, the focus relates to decreasing fuel poverty and improving energy efficiency in housing; while for SDG3 and SDG4, there is emphasis on promoting sustainable (local and carbon-neutral) food systems and nutritious diets. Despite the co-benefits of blue and green infrastructure to health and wellbeing, low coverage was also found related to clean water and sanitation (SDG6) (3\%) and regarding the protection of ecosystems on land (SDG15) $(2 \%)$ or below water (SDG14) (1\%).

\subsection{Nottingham}

The analysis for Nottingham is based on the document "Carbon Neutral Nottingham, 2020-2028 Action Plan" that was set up with a strong focus on carbon reduction and removal but also on resilience, adaptation, ecology, and biodiversity.

The text analysis showed that the most prominent SDGs are those around sustainable cities and communities (SDG11) (16\%), responsible consumption and production (SDG12) $(11 \%)$, and affordable and clean energy (SDG7) (11\%). This matched well with intentions set out in the framework description, which highlight that the plan is based on an integrative approach that links sustainability with wider social and economic considerations to identify and realize a range of co-benefits. The goals were to be achieved through a flexible approach based on existing and new partnerships and collaborations. This is also evident in the text analysis results, where SDG17 (partnerships for the goals) scored quite high (9\%), along with SDG9 (industry, innovation, and infrastructure) (7\%). 
Fewer matches were found for SDGs that arguably have less direct links to climate change, such as those focusing on the societal themes, such as SDG1 (no poverty) (2\%), SDG2 (no hunger) (3\%), SDG4 (quality education) ( $2 \%$ ), and SDG10 (reduced inequalities) $(0 \%)$. Ecology-based themes SDG14 (life below water) and SDG15 (life on land) also had low scores ( $0 \%$ and $1 \%$ respectively). Surprisingly, SDG13 (Climate action) also scored relatively low (4\%); but of course, many of the plans and approaches for the high scoring SDGs around sustainability and energy, and the plans focusing on carbon reduction, are in fact designed to contribute to positive climate action.

\section{Discussion and Conclusions}

This paper used simple text analysis of key words and related mapping techniques to illustrate the integration of the SDGs into climate action plans in Bristol and Nottingham, UK, as well as Kawasaki and Kyoto, Japan. The text analysis indicated that there is limited integration across the climate plans with some SDGs-for example, few references establish a link between gender and climate change. Moreover, there were significant differences between UK and Japanese cities. While the British cities displayed greater integration of SDG11 (sustainable cities and communities) and SDG12 (sustainable consumption and production), the Japanese cases emphasized SDG7 (affordable and clean energy) and SDG8 (decent work and economic growth). Finally, in many ways the types of linkages made in Kyoto resembled the UK cities more than Kawasaki.

While this analysis was illuminating, it was not without shortcomings. These limitations included that the word counting and mapping offered only one perspective of the relative importance of key terms. It is possible, for instance, that although a term might not appear frequently, it may also be positioned centrally in climate plans. Further, there is a possibility that some terms may appear less prominent because they are concentrated in one section. Illustrating the need to look more closely at the text, Kyoto's plans arguably pay more attention to integration than was revealed by word counting because it explicitly states which of its 20 promotion policies and six fields of action are aligned with specific SDGs. The above possibilities underline the need to supplement the text analysis with careful reading of text near keywords and the plans in its entirety.

Another set of limitations involves the selection of the keywords. This article made efforts to identify terms that were representative of pertinent SDGs. However, there may be other terms that are better aligned with actual city planner views on the SDGs. For instance, while the text analysis did not yield any matching result for SDG5 (gender equality), Kyoto's plan indicates it will promote environmentally friendly business and work styles aimed at empowering women. A related limitation is that any given climate plan remains a plan on paper. On the ground, implementation of the plan may actually result in a greater focus on areas where references are less discrete but significant actions are undertaken regardless. In the above cases, not only a careful review of the plan, but more in-depth interviews with relevant city officials would be helpful in better clarifying the intentions and intended results of the plans (note that initial interviews were conducted to supplement the text analysis featured in this article).

Even with these limitations, the inferences drawn from the text analysis suggest some ways forward for this kind of research. One possible set of next steps would involve looking more closely at how seemingly underrepresented linkages could be given more weight in future revisions of the plans. For example, it may be useful to bring in gender experts to review amendments of the plans or engage more closely with agencies responsible for social affairs. A second set of follow up actions could involve building within-country and cross-national city to city relationships that facilitate peer learning and knowledge exchanges on SDG and climate change integration. The four cities surveyed in this paper may be logical candidates for sharing climate plans and related experiences with each other.

An additional final point concerns extending the text analysis used in this research to more cities. One of the strengths of the text analysis is that it can be applied to a relatively large sample of cities with a limited investment of time and resources. Further, 
although care should be taken in reviewing the results of a large-n text analysis of cities, some identified patterns could help guide national policymakers on areas where cities may require additional technical and policy support to understand and take action on climate change and sustainable development priorities. Such cooperation might also help central governments understand where they could strengthen integration with the SDGs in national climate plans.

Author Contributions: Conceptualization, S.B. and E.Z.; methodology, L.O.-M., F.O.-M. and T.Y.; formal analysis, L.O.-M., F.O.-M., B.P. and T.Y.; investigation, L.O.-M., F.O.-M., B.P. and R.N.; writingE.Z., M.H., L.O.-M., F.O.-M. and B.P.; writing—review and editing, S.B., M.H. and E.Z. All authors have read and agreed to the published version of the manuscript.

Funding: This research was funded by UK Research and Innovation, grant number ES/S013547/1Networking grant for UK-Japan research collaboration titled "Integrating the sustainable development goals into climate planning in British and Japanese cities".

Institutional Review Board Statement: The study was conducted according to the guidelines of the Declaration of Helsinki, and approved by the Ethics Committee of the Faculty of Computing, Engineering and Media of De Montfort University (1819/514, 15 August 2019).

Informed Consent Statement: Not applicable as no human participants were involved in the data collection process.

Data Availability Statement: Not applicable.

Acknowledgments: The authors gratefully acknowledge the funding for staff time from their respective organizations. We also gratefully acknowledge the APC waiver given by MDPI for publishing this paper.

Conflicts of Interest: The authors declare no conflict of interest.

\section{References}

1. Bestill, M.M.; Bulkeley, H. Cities and the multilevel governance of global climate change. Glob. Gov. A Rev. Multilater. Int. Organ. 2006, 12, 141-160.

2. C40 Cities. Why Cities? Ending Climate Change Begins in the City. 2012. Available online: https:/ /www.c40.org/ending-climatechange-begins-in-the-city (accessed on 1 June 2021).

3. Rosenzweig, C.; Solecki, W.; Hammer, S.A.; Mehrotra, S. Cities lead the way in climate-change action. Nature 2010, 467, $909-911$. [CrossRef] [PubMed]

4. Fuhr, H.; Hickmann, T.; Kern, K. The role of cities in multi-level climate governance: Local climate policies and the $1.5^{\circ} \mathrm{C}$ target. Curr. Opin. Environ. Sustain. 2018, 30, 1-6. [CrossRef]

5. United Nations Climate Change Secretariat. Opportunities and Options for Integrating Climate Change Adaptation with Sustainable Development Goals and the Sendai Framework for Disaster Risk Reduction 2015-2030; United Nations Climate Change Secretariat: Bonn, Germany, 2017.

6. Zusman, E.; Nakano, R.; Hengesbaugh, M.; Yoshida, T.; Ortiz-Moya, F. Integrating the Sustainable Development Goals Into Urban Climate Plans: Insights from Japan. In Proceedings of the International Conference on Energising the SDGs through Appropriate Technology and Governance; De Montfort University: Leicester, UK, July 2019.

7. World Bank. Urban Development. 2021. Available online: https://www.worldbank.org/en/topic/urbandevelopment/overview (accessed on 20 April 2021).

8. Balsari, S.; Dresser, C.; Leaning, J. Climate Change, Migration, and Civil Strife. Curr. Environ. Health Rep. 2020, 7, $404-414$. [CrossRef] [PubMed]

9. GIZ, UN-Habitat and GenderCC. Gender and Urban Climate Policy: Gender Sensitive Policies Make a Difference; GIZ, UN-Habitat and GenderCC: Bonn, Germany, 2015.

10. Dong, L.; Liu, Z.; Bian, Y. Match Circular Economy and Urban Sustainbility: Re-investigating Circular Economy Under Sustainable Development Goals (SDGs). Circ. Econ. Sustain. 2021, 1-14. [CrossRef]

11. Peters, K.; Dupar, M.; Opitz-Stapleton, S.; Lovell, E.; Budimir, M.; Brown, S.; Cao, Y. Climate Change, Conflict and Fragility: Information and Analysis to Support Programme Design Scoping for the Climate and Resilience Framework Programme (CLARE); ODI: London, UK, 2020.

12. Nerini, F.F.; Tomei, J.; Seng To, L.; Bisaga, I.; Parikh, P.; Black, M.; Borrion, A.; Spataru, C.; Castán-Broto, V.; Anandarajah, G.; et al. Mapping synergies and trade-offs between energy and Sustainable Development Goals. Nature Energy 2018, 3, 10-15. [CrossRef]

13. Nilsson, M.; Griggs, D.; Visbeck, M. Map the interactions of sustainable development goals. Nature 2016, 534, 320-322. [CrossRef] [PubMed] 
14. Breu, T.; Bergöö, M.; Ebneter, L.; Pham-Truffert, M.; Bieri, S.; Messerli, P.; Ott, C.; Bader, C. Where to begin? Defining national strategies for implementing the 2030 Agenda: The case of Switzerland. Sustain. Sci. 2021, 16, 183-201. [CrossRef]

15. Tremblay, D.; Gowsy, S.; Riffon, O.; Boucher, J.F.; Dubé, S.; Villeneuve, C. A Systemic Approach for Sustainability Implementation Planning at the Local Level by SDG Target Prioritization: The Case of Quebec City. Sustainability 2021, 13, 2520. [CrossRef]

16. QSR International. NVivo Qualitative Data Analysis Software, Version 12. Available online: https://www.qsrinternational.com/ nvivo-qualitative-data-analysis-software/home/ (accessed on 21 March 2021).

17. City of Kyoto. Miyakoshi Chikyūondankataisaku Keikaku <2021-2030> (an); City of Kyoto: Kyoto, Japan, 2021.

18. Low, M. Eco-Cities in Japan: Past and Future. J. Urban Technol. 2013, 20, 7-22. [CrossRef]

19. City of Kawasaki. Kawasaki-shi Chikyūondankataisaku Suishin Jisshi Keikaku, Dai 1 kikan (2018-nendo 2021-nendo); City of Kawasaki: Kawasaki, Japan, 2018.

20. Bristol City Council. The Population of Bristol; Bristol City Council: Bristol, UK, 2020.

21. Bristol One City Environmental Sustainability Board. Bristol One City Climate Strategy a Strategy for a Carbon Neutral, Climate Resilient Bristol by 2030. February 2020. Available online: https://www.bristolonecity.com/wp-content/uploads/2020/02/onecity-climate-strategy.pdf (accessed on 19 January 2021).

22. European Commission. Bristol-2015, Environment; European Commission: Brussels, Belgium, 2015; Available online: https: / / ec.europa.eu/environment/europeangreencapital/winning-cities/2015-bristol/ (accessed on 29 April 2021).

23. Bristol One City. Bristol One City Plan, A Plan for Bristol to 2050; Bristol One City: Bristol, UK, January 2020. Available online: https:/ / www.bristolonecity.com/wp-content/pdf/BD11190-One-CIty-Plan-web-version.pdf (accessed on 20 January 2021).

24. MacLoad, A.; Fox, S. Bristol and the SDGs, A Voluntary Local Review Progress 2019; Cabot Institute for the Environment, University of Bristol: Bristol, UK, 2019.

25. REMOUrban. REMOUrban, REgeneration MOdel for Smart URBAN Transformation; REMOUrban: Cartif Technology Centre: Boecillo, Spain, 2021.

26. Nottingham City Council. Carbon Neutral Nottingham Action Plan 2020-2028; Nottingham City Council: Nottingham, UK, 2020. 